\title{
Benzophenone Suppression of Quercetin Antioxidant Activity towards Lipids under UV-B Irradiation Regime: Detection by HPLC Chromatography
}

\author{
Jelena S. Stanojević, Dejan Z. Marković, and Jelena B. Zvezdanović \\ Faculty of Technology, University of Niš, 124 Bulevar Oslobodjenja, 16000 Leskovac, Serbia \\ Correspondence should be addressed to Dejan Z. Marković; dejan_markovic57@yahoo.com
}

Received 4 June 2013; Revised 8 August 2013; Accepted 26 August 2013

Academic Editor: Wieslaw Wiczkowski

Copyright (C) 2013 Jelena S. Stanojević et al. This is an open access article distributed under the Creative Commons Attribution License, which permits unrestricted use, distribution, and reproduction in any medium, provided the original work is properly cited.

\begin{abstract}
Quercetin, a well-known flavonoid antioxidant, has been employed to control benzophenone-sensitized peroxidation of the lipid mixture in methanol solution, induced by continuous UV-B irradiation. Surprisingly, the detected quercetin antioxidant activity was almost negligible. The presented data suggests that the reason is not in its own UV-B-induced degradation but rather in its interrelationship with benzophenone during UV-B stress. On the other side of this relationship, benzophenone anticipated sensitizing role towards lipids; that is, the initiation of lipid peroxidation has been affected as well. These results, obtained by HPLC chromatography, partly confirm but partly relativize to some extent recent results obtained with the same system by spectrophotometric method.
\end{abstract}

\section{Introduction}

It has already been widely recognized that UV-B radiation, the most damaging part of total natural sunlight spectrum $(280-320 \mathrm{~nm})$, induces events which affect some crucial biologically important processes of global importance such as DNA replication $[1,2]$ or photosynthesis $[3,4]$. It has also been especially recognized as one of the major agents to initiate a lot of harmful free radicals-mediated processes, such as lipid peroxidation (LP). Lipid peroxidation is a free radical chain reaction (Type I), or it occurs through a nonradical pathway (Type II), by direct reaction with singlet oxygen created in the presence of a photosensitizer [5-9].

In a form of chain reaction, lipid peroxidation consists of an initiation step (leading to formation of lipid radicals $-\mathrm{L}^{*}$ ), a propagation step (where lipid radicals react with oxygen to form lipid peroxy radicals- $\mathrm{LOO}^{\circ}$ ), and a termination step (formation of dienes type lipid hydroperoxides- $\mathrm{LOOH}$ ) $[8,10]$. Lipid peroxidation initiators belong to reactive oxygen species (ROS) like hydroxy radicals $\left(\mathrm{OH}^{*}\right)$ or peroxy radicals (ROO ${ }^{\circ}$. They can be created through different pathways, including variety of external stresses [8], implying very commonly an external radiation [10-12]; in case of UVirradiation, LP may include a special type of LP initiators photosensitizers such as benzophenone (BZP), in very different media [13-15].

Photochemical reactions of benzophenone (BZPFigure 1), including $\mathrm{H}$-abstraction by its long-lived triplet state [13-15], have been relatively long-known in organic photochemistry. The related mechanisms are very complex and depend on particular solvent [16-18] or on particular BZP interactive compound in the given solvent $[19,20]$. Upon the absorption of UV-light, benzophenone may reach its long-lived triplet state $\left({ }^{3} \mathrm{BZP}\right)$, very reactive toward its surroundings (e.g., phospholipids mixture and quercetin), including a direct reaction with lipids; this interaction results in the production of lipid radicals $\left(\mathrm{L}^{\circ}\right),(1)$, which is the initiation step of lipid peroxidation (LP) chain reaction [21] as follows:

$$
{ }^{3} \mathrm{BZP}+\mathrm{LH} \longrightarrow \mathrm{BZPH}+\mathrm{L}^{\cdot}
$$

$\left({ }^{3} \mathrm{BZP}\right.$-triplet state of benzophenone; $\mathrm{BZPH}-\mathrm{BZP}-$ ketyl radical; $\mathrm{LH}$ - unsaturated lipid; $\mathrm{L}^{\circ}$-lipid radical). 
<smiles>O=C(c1ccccc1)c1ccccc1</smiles>

FIgURE 1: Structures of quercetin (left) and benzophenone (right).

On the other hand, lipid peroxidation is mostly controlled by antioxidants action in vivo. Many biomolecules (and classes of biomolecules) serve as antioxidants including flavonoids $[22,23]$ and quercetin (QC) among them (Figure 1). The updated studies connect high flavonols antioxidant activity with the presence of $\mathrm{OH}$-group in $\mathrm{C}$-ring 3position, in combination with catechol B-ring structure [22, 24-27].

Quercetin and its glycosides have been reportedly synthesized in plants, as a part of its total response toward UVradiation to prevent an extended induced damage [28, 29]. Quercetin absorbs UV radiation with absorbance maxima in the UV-A $\left(\lambda_{\max }=365 \mathrm{~nm}, \varepsilon=28,400 \mathrm{~mol}^{-1} \mathrm{dm}^{3} \mathrm{~cm}^{-1}\right)$ and $\operatorname{UV}-\mathrm{C}$ range $\left(\lambda_{\max }=256 \mathrm{~nm}, \varepsilon=28,300 \mathrm{~mol}^{-1} \mathrm{dm}^{3} \mathrm{~cm}^{-1}\right)$. However, flavonoids can also act as free-radical scavengers to prevent oxidative skin damage [30-34], and their topical application has met considerable interest [35-38]; generally, they are of significant interest for medicinal chemistry [39, 40].

So, quercetin may act as a protector against UV radiation through (i) either absorption (preventive, inhibition mode) or (ii) scavenging activities ("chain-breaking", antioxidant mode). In the former case, the absorbed UV energy may be dissipated as heat [41] or converted into quercetin decomposition products, in vitro as in vivo [27, 42, 43]; in the latter case-quercetin scavenges already-created free radicals (such as lipid peroxy radicals, $\mathrm{LOO}^{\circ}$ ), mostly by hydrogen atom transfer mechanism, shown in (2) $[44,45]$ as follows:

$$
\mathrm{Fl}-\mathrm{OH}+\mathrm{L}^{\bullet} \longrightarrow \mathrm{Fl}^{-\mathrm{O}^{\bullet}}+\mathrm{LH}
$$

The oxidized $\mathrm{Fl}-\mathrm{O}^{\bullet}$ radical (which can be stabilized by one intramolecular $\mathrm{H}$-bonding in the B-ring: $-\mathrm{O}^{\bullet} \cdots \mathrm{H}-\mathrm{O}-$ ) [45] may react with a second radical $\left(\mathrm{L}^{\circ}\right)$ acquiring a quite stable quinone structure [23].

In our former paper, we have tested QC antioxidant ability toward lipids in the presence of sensitizing BZP (as LP initiator) in methanol solution under continuous UV$B$ irradiation by spectrophotometric method [46]. We have got somewhat surprising conclusions on QC activity in the presence of BZP (under UV-B stress), which led us to reexamine the same system $(\mathrm{BZP}+\mathrm{QC}+$ lipids, in $\mathrm{MeOH})$ by HPLC chromatography, to confirm or at least relativize these conclusions. HPLC separation should provide "cleaner" picture since providing satisfying separation of the involving species eliminates partial overlapping of the absorption spectra and potentially doubtful related interpretations.

\section{Materials and Methods}

Phospholipids (Phospholipon 90) were gifted by PHOSPHOLIPID GmbH, Köln, Germany. According to the accompanied declaration, the mixture content is Phospholipon 90 (PL90)-phosphatidylcholine 98\%, lysophosphatidylcholine 2.1\%; fatty acid composition: palmitic acid $12 \pm 2 \%$, stearic acid $3 \pm 1 \%$, oleic acid $10 \pm 3 \%$, linoleic acid $66 \pm 5 \%$, linolenic acid $5 \pm 2 \%$, peroxide value max. 1.3. The phospholipids mixtures were kept in dark to prevent at least the photooxidation process. Benzophenone (BZP) was obtained from Sigma Chemical Co. (St. Louis, USA). Standard of quercetin was purchased from Merck (Darmstadt, Germany).

2.1. The Samples. The (studied system) components' final concentrations in methanol solution were phospholipids, $1.3 \cdot 10^{-3} \mathrm{~mol} \mathrm{dm}{ }^{-3}$; quercetin, $1 \cdot 10^{-4} \mathrm{~mol} \mathrm{dm}{ }^{-3}$; BZP, $1.1 \cdot 10^{-4}$ mol $\mathrm{dm}^{-3}$. The $\mathrm{pH}$ was 7.6 , and the experiments were done at room temperature.

2.2. UV-Irradiation. Continuous irradiations of samples in methanol were performed in cylindrical photochemical reactor "Rayonnet," with 10 symmetrically placed lamps with emission maxima at $300 \mathrm{~nm}$ (UV-B). The samples were irradiated in quartz closed cuvettes $(1 \times 1 \times 4.5 \mathrm{~cm})$ placed on rotating circular holder. The total measured energy flux was $15.0 \mathrm{~W} \mathrm{~m}^{-2}$ for $300 \mathrm{~nm}$ at $10 \mathrm{~cm}$ distance from the lamps. The methanol solutions of BZP only and phospholipids (with or without BZP), as a kind of blank, were irradiated and analyzed simultaneously with the phospholipids/quercetin and phospholipids/quercetin/BZP mixtures.

2.3. HPLC. The irradiated samples were immediately analysed with Agilent 1100 Series system (Waldbron, Germany), on Zorbax Eclipse XDB-C18 column, $4.6 \times 250 \mathrm{~mm}, 5 \mu \mathrm{m}$, with DAD detector. The samples volume was $20 \mu \mathrm{L}$. The isocratic regime with $100 \%$ methanol was applied, under flow of $1.0 \mathrm{~mL} / \mathrm{min}$. The column temperature was $25^{\circ} \mathrm{C}$. The chromatograms were recorded at $210 \mathrm{~nm}$ (unoxidized lipids), $234 \mathrm{~nm}$ (peroxides-[47, 48]), $250 \mathrm{~nm}$ (BZP), $295 \mathrm{~nm}$ (possible quercetin decomposition products) and $371 \mathrm{~nm}$ (quercetin).

Most of the experiments (UV-irrad., followed by HPLC analysis) were repeated at least once more; some of them were triplicated.

\section{Results and Discussion}

Structures of benzophenone and quercetin are shown in Figure 1.

The changes in the samples recorded chromatograms as a result of increased UV-B irradiation periods are shown in Figures 2(a)-4(a): Figure 2(a) shows degradation of quercetin (recorded at $371 \mathrm{~nm}$ ), and Figure 3(a) shows degradation of BZP (recorded at $250 \mathrm{~nm}$ ), while Figure 4(a) documents a proliferation of LP process, that is, a rise in peroxides production (recorded at $234 \mathrm{~nm}$ ). 


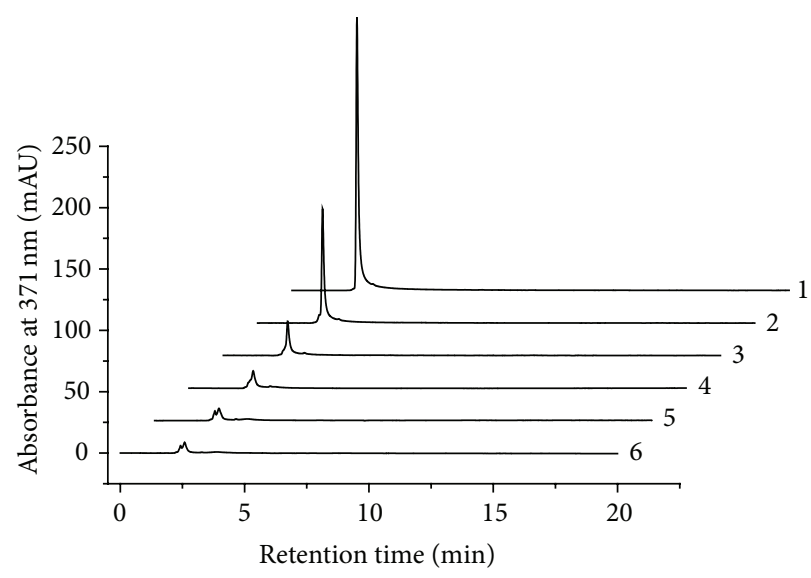

1: QC-BZP-PL90, not irradiated 2: QC-BZP-PL90, UV-B, $15 \mathrm{~min}$ 3: QC-BZP-PL90, UV-B, $30 \mathrm{~min}$ 4: QC-BZP-PL90, UV-B, $45 \mathrm{~min}$ 5: QC-BZP-PL90, UV-B, $60 \mathrm{~min}$ 6: QC-BZP-PL90, UV-B, 75 min

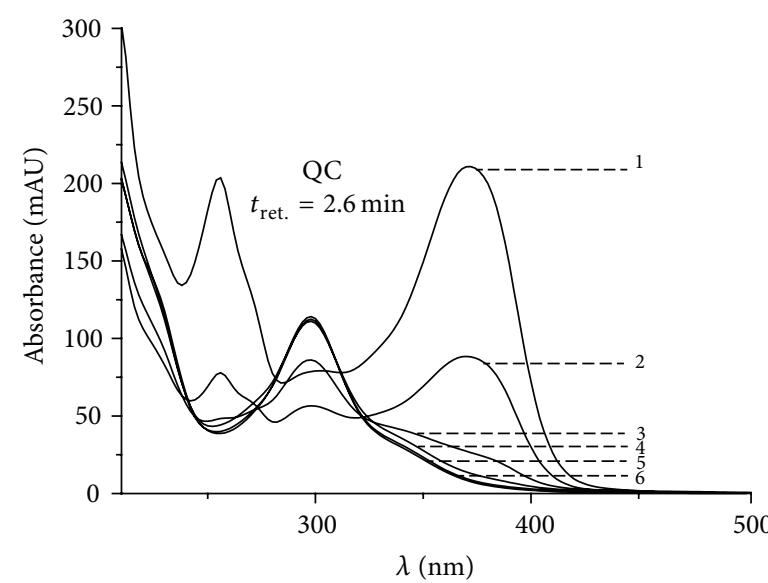

1: QC, not irradiated 2: QC, UV-B, $15 \mathrm{~min}$ 3: QC, UV-B, $30 \mathrm{~min}$ 4: QC, UV-B, $45 \mathrm{~min}$ 5: QC, UV-B, $60 \mathrm{~min}$ 6: QC, UV-B, $75 \mathrm{~min}$

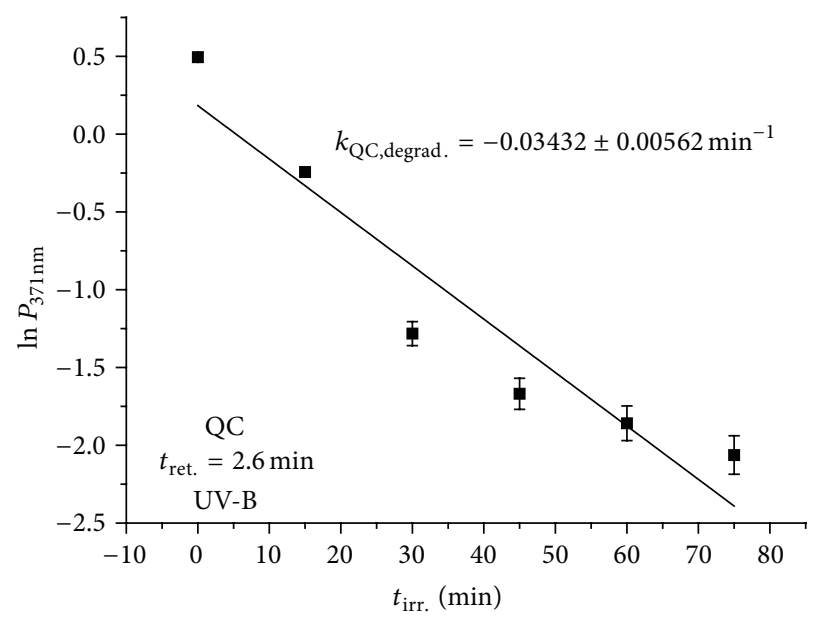

(c)

FIGURE 2: Degradation (bleaching) of quercetin from the UV-B-irradiated sample, that is, quercetin/BZP/phospholipids mixture in methanol. (a) The recorded samples chromatograms recorded at $371 \mathrm{~nm}$ (quercetin retention time, $t_{\text {ret. }}$, of $2.6 \mathrm{~min}$ ). (b) Changes in quercetin absorption spectra taken from the upper (a) chromatogram (quercetin peak at $t_{\text {ret. }}=2.6 \mathrm{~min}$ ), as a result of the increasing UV-B irradiation periods $\left(t_{\text {irr. }}\right)$. (c) Kinetics of UV-B irradiation-induced bleaching, followed through a decrease of quercetin peak $\left(t_{\text {ret. }}=2.6\right.$ min) integrated areas as a result of the increased UV-B irradiation periods, $\ln P_{371 \mathrm{~nm}}=f\left(t_{\text {irr. }}\right)$. The corresponding bleaching rate constant and the related error bars are shown in the plot.

The corresponding changes in the absorption spectra of quercetin, BZP, and the two peroxides (taken for the corresponding peaks of the recorded HPLC chromatograms) are shown in Figures 2(b), 3(b), 4(b), and 4(c), respectively. The difference in the absorption spectra of the two detected peroxides-the absence and the presence of the "right shoulder" with $A_{\max }$ around $280 \mathrm{~nm}$ (Figures 4(b) and 4(c), resp.)-suggests they have somewhat different structures; still the basic peroxide diene chromophore, responsible for $A_{\max }$ at $234 \mathrm{~nm}$, is obviously present in both cases.
The related kinetic plots referring to the degradation of quercetin, BZP, and production of the two peroxides are given in Figures 2(c), 3(c), 4(d), and 4(e), respectively.

The slopes calculated from kinetic ln-plots shown in Figures 2(c), 3(c), 4(d), and 4(e) representing the rates of quercetin degradation, BZP degradation, and the two peroxides production in the UV-B irradiated samples are shown in Tables $1(\mathrm{a})$ and $1(\mathrm{~b})$, respectively.

In our recent publication [49], we have compared stability of two flavonoid components, quercetin and rutin, in solution 


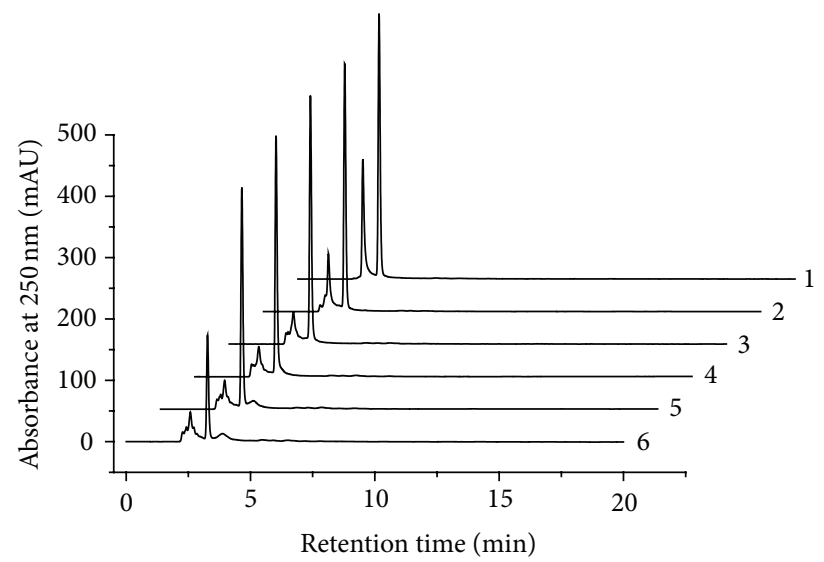

1: QC-BZP-PL90, not irradiated 2: QC-BZP-PL90, UV-B, $15 \mathrm{~min}$ 3: QC-BZP-PL90, UV-B, $30 \mathrm{~min}$ 4: QC-BZP-PL90, UV-B, $45 \mathrm{~min}$ 5: QC-BZP-PL90, UV-B, $60 \mathrm{~min}$ 6: QC-BZP-PL90, UV-B, $75 \mathrm{~min}$

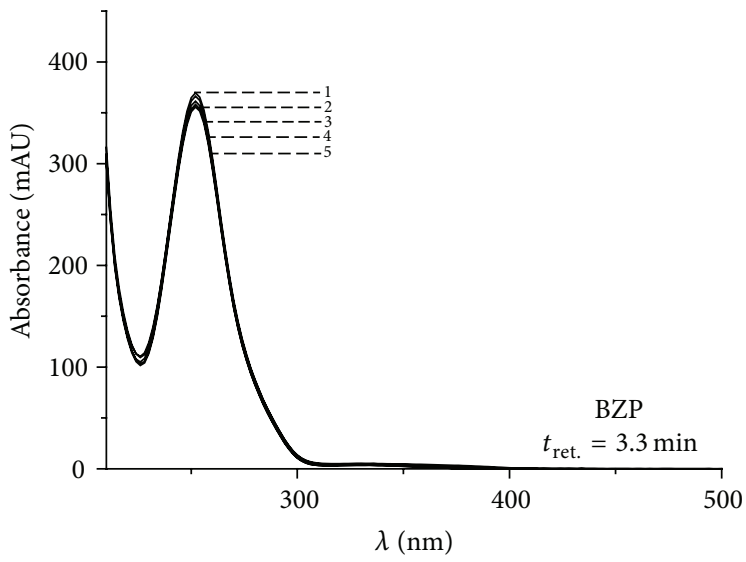

1: BZP, not irradiated 2: BZP, UV-B, $15 \mathrm{~min}$ 3: BZP, UV-B, $30 \mathrm{~min}$ 4: BZP, UV-B, $45 \mathrm{~min}$ 5: BZP, UV-B, $60 \mathrm{~min}$

(a)

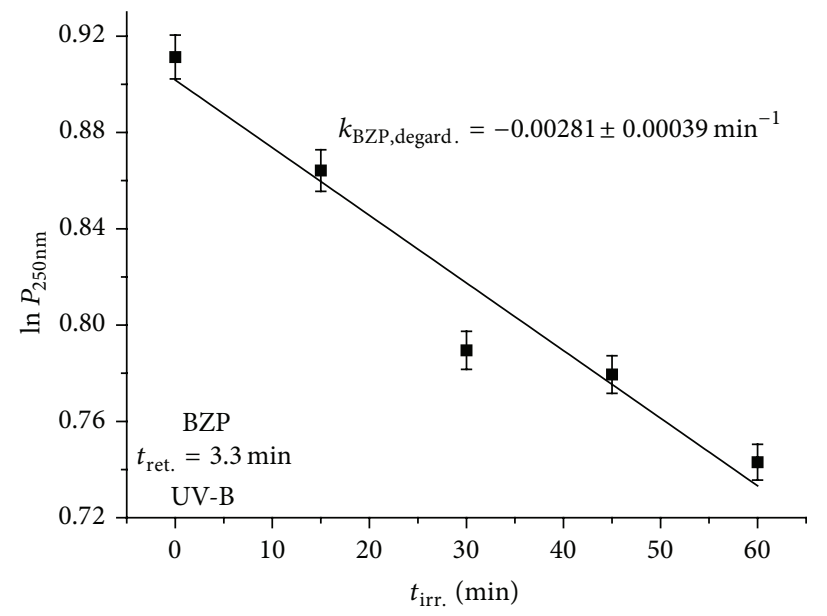

(c)

FIgURE 3: Degradation (bleaching) of benzophenone from the UV-B-irradiated sample, that is, quercetin/BZP/phospholipids mixture in methanol. (a) The recorded samples chromatograms recorded at $250 \mathrm{~nm}$ (BZP retention time, $t_{\text {ret. }}$, of $3.3 \mathrm{~min}$ ). (b) Changes in BZP absorption spectra taken from the upper (a) chromatogram (BZP peak at $t_{\text {ret. }}=3.3 \mathrm{~min}$ ), as a result of the increasing UV-B irradiation periods $\left(t_{\text {irr. }}\right.$ ). (c) Kinetics of UV-B irradiation-induced bleaching, followed through a decrease of BZP peak $\left(t_{\text {ret. }}=3.3\right.$ min $)$ integrated areas as a result of the increased UV-B irradiation periods, $\ln P_{250 \mathrm{~nm}}=f\left(t_{\text {irr. }}\right)$. The corresponding bleaching rate constant and the related error bars are shown in the plot.

toward UV-irradiation (from the three subranges UV-A, UV$\mathrm{B}, \mathrm{UV}-\mathrm{C})$, as well as their antioxidant activities in the presence of lipoidal mixture (i.e., lecithin) as the "protection target"; despite the lower QC stability against UV-irradiation, its antioxidant ability to protect lipid mixture from peroxidation was found to be higher compared to rutin. In addition, we have recently observed that UV continuous irradiation of quercetin and rutin in solution led to creation of products which absorb in spectral regions between 250 and $350 \mathrm{~nm}$ [50]. And, in the most recent report [46], we have added benzophenone in QC/phospholipids mixture. The purpose of
BZP involvement in the system was to produce more radicals, for example, lipid radicals since it is not only very efficient but very selective sensitizer $[5,13,14]$. Therefore, the new system (BZP + QC + lipids, in $\mathrm{MeOH}$ ) contributed to some extent to better understanding of both quercetin protective actions during prolonged continuous UV-irradiation: the preventive one (studied through UV-induced degradation) as well as the antioxidant one (studied by tracing expansion of UV-induced LP process, expressed through creation of LP peroxides dienes structures in the presence and in the absence of benzophenone). While quercetin suppression effect on LP 


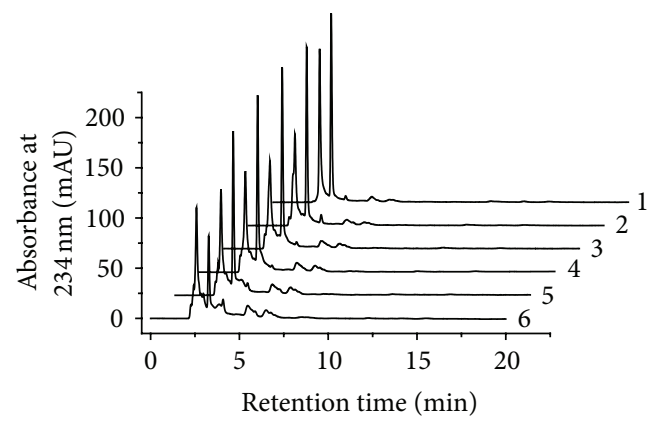

1: QC-BZP-PL90, not irradiated 2: QC-BZP-PL90, UV-B, $15 \mathrm{~min}$ 3: QC-BZP-PL90, UV-B, $30 \mathrm{~min}$ 4: QC-BZP-PL90, UV-B, $45 \mathrm{~min}$ 5: QC-BZP-PL90, UV-B, $60 \mathrm{~min}$ 6: QC-BZP-PL90, UV-B, $75 \mathrm{~min}$

(a)
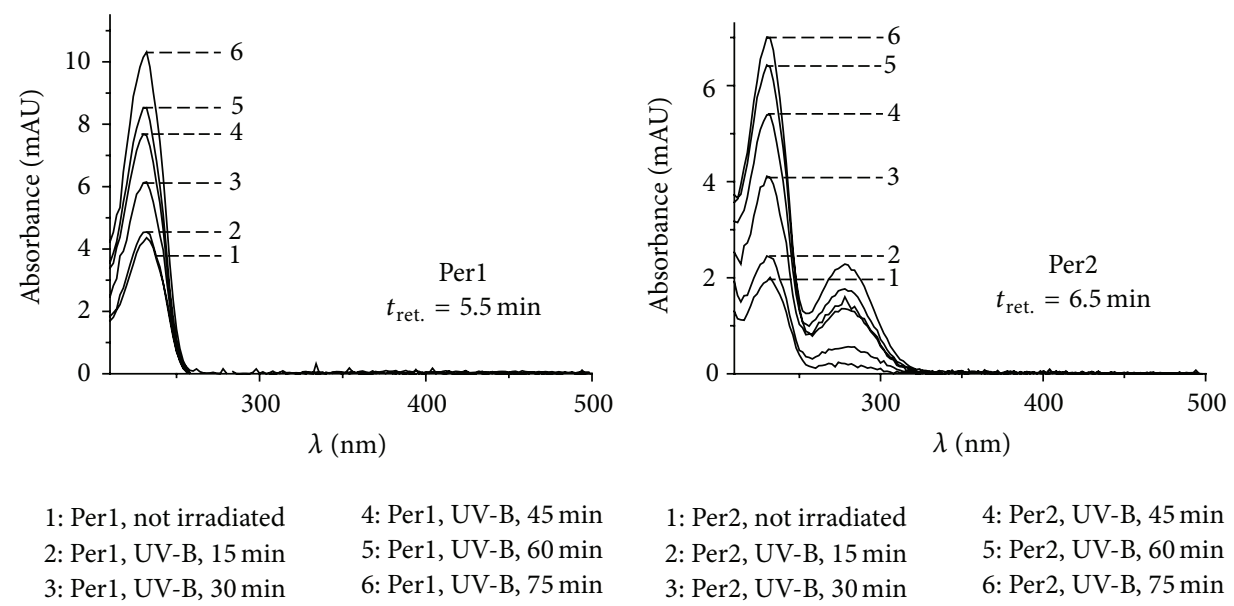

(b)

(c)

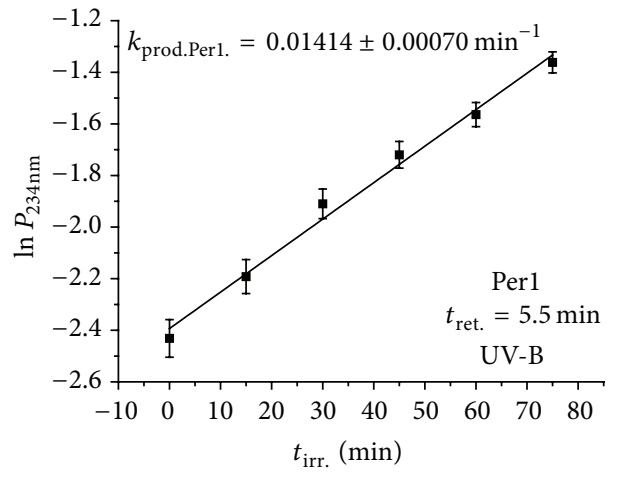

(d)

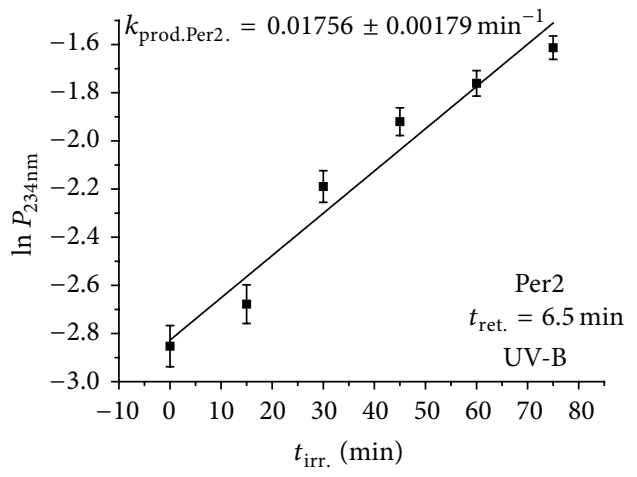

(e)

FIGURE 4: Formation of lipid peroxides in the UV-B-irradiated sample, that is, quercetin/BZP/phospholipids mixture in methanol. (a) The recorded samples chromatograms recorded at $234 \mathrm{~nm}$ (peroxides retention times, $t_{\text {ret. }}$, of 5.5 and $6.5 \mathrm{~min}$ ). ((b) and (c)) changes in the two peroxides absorption spectra taken from the upper (a) chromatogram (Perl $t_{\text {ret. }}=5.5 \mathrm{~min}$, Per $2 t_{\text {ret. }}=6.5 \mathrm{~min}$ ), as a result of the increasing UV-B irradiation periods $\left(t_{\text {irr. }}\right)$. ( (d) and (e)) Kinetics of rise of the two peroxides peaks (Perl $t_{\text {ret. }}=5.5$ min, Per2 $t_{\text {ret. }}=6.5$ min) integrated areas as a result of the increased UV-B irradiation periods, $\ln P_{234 \mathrm{~nm}}=f\left(t_{\mathrm{irr}}\right)$. The corresponding rate constants and the related error bars are shown in the plots. 
TABLE 1: (a) Rate constants for degradation of quercetin (QC) and benzophenone (BZP) ( $\mathrm{min}^{-1}$ ) obtained from the slopes of the 1st order linear plots, $\ln P_{371 / 250 \mathrm{~nm}}=f\left(t_{\text {irr. }}\right)$, representing proportional decrease of QC and BZP concentrations as a result of the increasing UV-B irradiation periods. $P_{371 / 250 \mathrm{~nm}}$ presents integrated areas of QC and BZP peaks, from the HPLC chromatograms (shown in Figures 2(a) and 3(a)) recorded at 371 and $250 \mathrm{~nm}$, respectively. (b) Rate constants for the two peroxides formation, obtained from the slopes of the 1st order linear plot, ln $P_{234 \mathrm{~nm}}=f\left(t_{\mathrm{irr}}\right)$, representing proportional increase of the two peroxides concentrations as a result of the increasing UV-B irradiation periods. $P_{234 \mathrm{~nm}}$ presents integrated areas of the peroxides peaks (Per1 $t_{\text {ret. }}=5.5 \mathrm{~min}$, Per2 $t_{\text {ret. }}=6.5 \mathrm{~min}$ ), from the HPLC chromatograms ( Figure 4(a)) recorded at $234 \mathrm{~nm}$.

\begin{tabular}{|c|c|c|c|}
\hline & $\mathrm{QC}+\mathrm{PL} 90+\mathrm{BZP}$ & $\mathrm{QC}+\mathrm{PL90}$ & $\mathrm{BZP}+\mathrm{PL90}$ \\
\hline $\begin{array}{l}\mathrm{QC} \\
t_{\text {ret. }}=2.6 \mathrm{~min}\end{array}$ & -0.03432 & -0.00332 & l \\
\hline $\begin{array}{l}\mathrm{BZP} \\
t_{\text {ret. }}=3.3 \mathrm{~min}\end{array}$ & -0.00281 & I & -0.01288 \\
\hline
\end{tabular}

(b) Peroxides production, $k_{\text {prod. Per }}, \min ^{-1}$

\begin{tabular}{lccc}
\hline & QC + PL90 + BZP & QC + PL90 & BZP + PL90 \\
\hline Per1 & 0.01414 & -0.00009 & 0.01734 \\
$t_{\text {ret. }}=5.5 \mathrm{~min}$ & & & 0.01473 \\
Per2 & 0.01756 & $/$ & \\
$t_{\text {ret. }}=6.5 \mathrm{~min}$ & & & \\
\hline
\end{tabular}

process has been proven, it was found that the suppression effect is less effective when BZP was present [46]; evidently, quercetin degradation was more favored in the presence of BZP. However, the deeper conclusions could not be offered partly because of the obvious limitations of the applied spectrophotometric method based on a clear overlapping of the involved species (BZP, quercetin, peroxides) absorption $\operatorname{spectra}\left(\lambda_{\max }=250 \mathrm{~nm}\right.$ for BZP, $234 \mathrm{~nm}$ for peroxides, 260 and $370 \mathrm{~nm}$ for quercetin). This report is one step ahead since the method has been changed; now, the same system has been analysed by HPLC chromatography providing a kinetic analysis of the clearly separated involved species. As in the cited two reports $[46,49]$, due to the complexity of the studied system, the mixture of BZP and lipids has been irradiated as a blank in order to evaluate, in the next step, LP control by quercetin during UV-B irradiation (290-320 nm).

The chromatograms recorded at the involved species absorption maxima (Figures 2(a), 3(a), and 4(a)) deal with the separated compounds; the kinetic plots (Figures 2(c), 3(c), $4(\mathrm{~d})$, and $4(\mathrm{e}))$ have been obtained from the corresponding peaks integrated areas, and the calculated rate constants for quercetin and BZP degradation as well as for the two peroxides (Per1 \& Per2) formation represent much "pure behavior," compared to at least partly "mixed behavior" reported in the former paper [46].

Prolonged continuous irradiation of quercetin in methanol (in the presence of lipid mixture and BZP) causes a gradual decrease of the corresponding integrated peak $\left(t_{\text {ret. }}=2.6 \mathrm{~min}\right)$ areas during increasing irradiation periods (Figure 2(a)); the corresponding kinetic plot (Figure 2(c)) and the changes in the corresponding absorption spectra shown in Figure 2(b) confirm this degradation pattern. This degradation pattern (of $\mathrm{QC}$ in $\mathrm{MeOH}$ ) has been already noted in our two previous reports, where QC decomposition into ring $\mathrm{C}$-opening products has been recorded by HPLC techniques [50] or by spectrophotometric method (in the last case in the presence of BZP, [46]), confirming the previous work (with $\mathrm{BZP}$ and $\mathrm{QC}$ in $\mathrm{MeOH}$ ) and the proposed mechanism of Fahlman and Krol [51] (it should be added at this place that the oxidation pattern of quercetin is highly dependent on the applied initiating mechanism, but the related details are out of scope of this paper $[52,53])$. However the real issue in QC degradation kinetics is the role of BZP. If one compares the QC degradation rate constants from Table $1(\mathrm{a})\left(k_{\mathrm{QC} \text {,degrad. }}\right)$ in the presence and in the absence of BZP (the last one obtained under absolutely the same chromatographic conditions, not shown), 0.03432 versus $0.00332 \mathrm{~min}^{-1}$, it is evident that BZP presence dramatically speeds up QC degradation. The same fact was seen in the previous report [46], when the same (BZP + $\mathrm{QC}+$ lipids) mixture was irradiated under the same UV irradiation regime, though the (degradation constants, in the presence and in the absence of BZP) relationship is not that huge as in this study (roughly, 3 versus 10). Still, having in mind objective limits of spectrophotometric method the HPLC data from Table 1(a) looks not only confirming but also more accurate. It is also important to note that the reported quercetin degradation rate constant in the presence of lipids but in the absence of BZP $\left(0.00332 \mathrm{~min}^{-1}\right)$ is in a logical agreement with the one obtained for QC degradation under the same (UV-B) conditions and in the same solvent, methanol, in the absence of all other species $\left(0.00183 \mathrm{~min}^{-1}\right)$ [50]; the latter one is obviously smaller, confirming quercetin antioxidant activity toward lipids before introduction of BZP.

However, it appears that not only BZP largely affects quercetin degradation (and so its antioxidant ability) but also its own main anticipated activity towards lipids [5, 13, 14]; BZP-sensitizing ( $\mathrm{H}$-abstraction) activity becomes almost 5 times slower in the presence of quercetin, rate constants for BZP degradation $\left(k_{\mathrm{BZP}, \text { degrad. }}\right)$ of 0.01288 and $0.00281 \mathrm{~min}^{-1}$, 
respectively (Table 1a, calculated from the kinetic plot shown in Figure 3(c)).

That clearly suggests that the cause has to be somehow related to BZP (i.e., ${ }^{3} \mathrm{BZP}$ )-QC mutual interaction; no other interaction can match an explosive ${ }^{3} \mathrm{BZP}$ attack to double bonds in the used lipoidal mixture and the abstraction of allylic and double-allylic $\mathrm{H}$-atoms $[5,13,14]$, especially having in mind high percentage of present linoleic acid (more than $50 \%$ ), with its two double bonds in each of the two hydrophobic branches.

As reported-quercetin has two absorption maximums, in UV-A $\left(\lambda_{\max }=372 \mathrm{~nm}\right)$ and UV-C $\left(\lambda_{\max }=260 \mathrm{~nm}\right)$ spectral ranges [49] which partly overlap with the applied UV-B irradiation range used in this work. In recently published paper, Fahlman et al. [51] studied UV-A and UV-B irradiation of quercetin in BZP-containing methanol solution, yielding an irreversible degradation, followed by formation of several C-ring-opened photoproducts; they noticed BZP impact on both, QC degradation as well as on photoproducts formation [51]; this confirms that BZP-QC connection is found in this work and in the previous report [46].

The other side of the anticipated BZP-QC interactions is a question of QC antioxidant activity against lipids: how much has it been affected by this interaction? To be able to evaluate the possible change, a blank experiment has been done with QC and the lipids (without BZP); from the corresponding slope (Figure Add-1 in Supplementary Materials available online at http://dx.doi.org/10.1155/2013/761675) for the peroxides production, a rate constant has been calculated $\left(k_{\text {prod. Per }}=-0.00009 \mathrm{~min}^{-1}\right.$, Table 1$)$. The linear decrease in the peroxides production represents an obvious QC-governing effect. However, when BZP is brought in the system, the situation dramatically changes. First of all, the sign of peroxides production has been changed, that is, reversed, from minus (-) in BZP absence to plus $(+)$ in its presence (Figures $4(\mathrm{~d})$ and 4(e)). In addition, the peroxides production rate constants, for the two detected and separated peroxides species, $k_{\text {prod. Per } 1}$ and $k_{\text {prod. Per } 2}$, are almost 200 times bigger. And, the most important, it is hard to see almost any QC antioxidant activity on BZP-induced lipid peroxidation (more expressed than in the former, [46], "spectrophotometric" report): the two peroxides production rate constants for the two peroxides peaks, Perl $t_{\text {ret. }}=5.5 \mathrm{~min}$ and Per $2 t_{\text {ret. }}=6.5 \mathrm{~min}$, obtained from kinetic plots shown in Figures 4(d) and 4(e) in the presence and in the absence of quercetin are almost the same $\left(0.01414\right.$ versus $0.01734 \mathrm{~min}^{-1}$ and 0.01756 versus $0.01473 \mathrm{~min}^{-1}$, Table 1).

\section{Conclusion}

To conclude, it appears that while a QC general control effect on LP process is not ultimately denied, the suppression is definitely not only less effective but practically absent when BZP is present. HPLC results obtained in this paper not only support spectrophotometric data obtained for the same system in the last report [46] (concerning this fact) but also strengthen it. The very newly found fact, that is, the novelty of this study (compared to [46]), is that suppression has the other side, a slower BZP sensitizing activity (against lipids as the target). This emphasizes a necessity of further efforts to determine more precisely BZP-QC relationship in the presence of lipids, under conditions of external continuous UV-B irradiation stress.

\section{Acknowledgments}

This work was supported by the Project on Development of Technology no. TR-34012 as well as under the Basic Investigations Project no. OI-172044 by the Ministry of Education and Science of the Republic of Serbia.

\section{References}

[1] M. Ichihashi, M. Ueda, A. Budiyanto et al., "UV-induced skin damage," Toxicology, vol. 189, no. 1-2, pp. 21-39, 2003.

[2] G. P. Pfeifer, Y. You, and A. Besaratinia, "Mutations induced by ultraviolet light," Mutation Research, vol. 571, no. 1-2, pp. 19-31, 2005.

[3] A. Teramura and L. Ziska, Photosynthesis and the Environment, Kluwer Academic, Dodrecht, The Netherlands, 1996.

[4] A. Strid, W. S. Chow, and J. M. Anderson, "Effects of supplementary ultraviolet-B radiation on photosynthesis in Pisum sativum," Biochimica et Biophysica Acta, vol. 1020, no. 3, pp. 260268, 1990.

[5] D. Markovic and L. Patterson, "Benzophenone-sensitized lipid peroxidation in linoleate micelles," Photochemistry and Photobiology, vol. 58, no. 3, pp. 329-334, 1993.

[6] N. Paillous and S. Fery-Forgues, "Interest of photochemical methods for induction of lipid peroxidation," Biochimie, vol. 76, no. 5, pp. 355-368, 1994.

[7] R. Wheatley, "Some recent trends in the analytical chemistry of lipid peroxidation," TrAC Trends in Analytical Chemistry, vol. 19, no. 10, pp. 617-628, 2000.

[8] A. Girotti, "Photosensitized oxidation of membrane lipids: reaction pathways, cytotoxic effects, and cytoprotective mechanisms," Journal of Photochemistry and Photobiology B, vol. 63, pp. 103-113, 2001.

[9] E. Niki, Y. Yoshida, Y. Saito, and N. Noguchi, "Lipid peroxidation: mechanisms, inhibition, and biological effects," Biochemical and Biophysical Research Communications, vol. 338, no. 1, pp. 668-676, 2005.

[10] J. Aikens and T. A. Dix, "Hydrodioxyl (perhydroxyl), peroxyl, and hydroxyl radical-initiated lipid peroxidation of large unilamellar vesicles (liposomes): comparative and mechanistic studies," Archives of Biochemistry and Biophysics, vol. 305, no. 2, pp. 516-525, 1993.

[11] L. R. C. Barclay and M. R. Vinqvist, "Membrane peroxidation: inhibiting effects of watersoluble antioxidants on phospholipids of different charge types," Free Radical Biology and Medicine, vol. 16, no. 6, pp. 779-788, 1994.

[12] Q.-T. Li, M. H. Yeo, and B. K. Tan, "Lipid peroxidation in small and large phospholipid unilamellar vesicles induced by water-soluble free radical sources," Biochemical and Biophysical Research Communications, vol. 273, no. 1, pp. 72-76, 2000.

[13] D. Markovic and L. Patterson, "Radical processes in lipids. Selectivity of hydrogen abstraction from lipids by benzophenone triplet," Photochemistry and Photobiology, vol. 49, no. 5, pp. 531-535, 1989. 
[14] D. Markovic, T. Durand, and L. Patterson, "Hydrogen abstraction from lipids by triplet states of derivatized benzophenone photosensitizers," Photochemistry and Photobiology, vol. 51, pp. 389-394, 1990.

[15] D. Markovic, "Benzophenone-sensitized peroxidation in compressed lipid monolayers at air-water interface," Collection of Czechoslovak Chemical Communications, vol. 66, pp. 1603-1614, 2001.

[16] C. Viltres Costa, M. A. Grela, and M. S. Chorio, "On the yield of intermediates formed in the photoreduction of benzophenone," Journal of Photochemistry and Photobiology A, vol. 99, pp. 51-56, 1996.

[17] M. von Raumer, P. Suppan, and P. Jacques, "Photoinduced charge transfer processes of triplet benzophenone in acetonitrile," Journal of Photochemistry and Photobiology A, vol. 105, no. 1, pp. 21-28, 1997.

[18] P. McGarry, C. Heitner, J. Schmidt et al., "A dramatic solvent effect on high-yield pulp yellowing inhibition for a benzophenone-based ultraviolet absorber," Journal of Photochemistry and Photobiology A, vol. 151, pp. 145-155, 2002.

[19] M. Dossot, X. Allonas, and P. Jacques, "Comparative timeresolved photoconductivity and absorption spectroscopy studies on dark secondary reactions following the photoreduction of benzophenone by triethylamine," Journal of Photochemistry and Photobiology A, vol. 128, pp. 47-55, 1999.

[20] Q. Q. Zhu and W. Schnabel, "Interaction of triplet-excited benzophenone with hindered amines and amino ethers: a laser flash photolysis study employing photoconductivity and light emission measurements," Journal of Photochemistry and Photobiology A, vol. 130, no. 2-3, pp. 119-125, 2000.

[21] D. Cvetkovic and D. Markovic, "Beta-carotene suppression of benzophenone-sensitized lipid peroxidation in hexane through additional chain-breaking activities," Radiation Physics and Chemistry, vol. 80, no. 1, pp. 76-84, 2011.

[22] K. E. Heim, A. R. Tagliaferro, and D. J. Bobilya, "Flavonoid antioxidants: chemistry, metabolism and structure-activity relationships," Journal of Nutritional Biochemistry, vol. 13, no. 10, pp. 572-584, 2002.

[23] P. G. Pietta, "Flavonoids as antioxidants," Journal of Natural Products, vol. 63, no. 7, pp. 1035-1042, 2000.

[24] D. Amić, D. Davidović-Amić, D. Bešlo, and N. Trinajstić, "Structure-radical scavenging activity relationships of flavonoids," Croatica Chemica Acta, vol. 76, pp. 55-61, 2003.

[25] D. P. Makris and J. T. Rossiter, "An investigation on structural aspects influencing product formation in enzymic and chemical oxidation of quercetin and related flavonols," Food Chemistry, vol. 77, no. 2, pp. 177-185, 2002.

[26] S. Erkoc, F. Erkoc, and N. Keskin, "Theoretical investigation of quercetin and its radical isomers," Journal of Molecular Structure, vol. 631, pp. 141-146, 2003.

[27] G. J. Smith, S. J. Thomsen, K. R. Markham, C. Andary, and D. Cardon, "The photostabilities of naturally occurring 5-hydroxyflavones, flavonols, their glycosides and their aluminium complexes," Journal of Photochemistry and Photobiology A, vol. 136, no. 1-2, pp. 87-91, 2000.

[28] Å. Strid and R. J. Porra, "Alterations in pigment content in leaves of pisum sativum after exposure to supplementary UV-B," Plant and Cell Physiology, vol. 33, no. 7, pp. 1015-1023, 1992.

[29] A. Strid, W. S. Chow, and J. M. Anderson, "UV-B damage and protection at the molecular level in plants," Photosynthesis Research, vol. 39, no. 3, pp. 475-489, 1994.
[30] J. H. Schoemaker, M. T. Schoemaker, H. Zijlstra, and F. A. van der Horst, "Treatment of erythropoietic protoporphyria with hydroxyethylrutosides," Dermatology, vol. 191, no. 1, pp. 36-38, 1995.

[31] P. S. Mortimer, “Therapy approaches for lymphedema," Angiology, vol. 48, no. 1, pp. 87-91, 1997.

[32] B. Choquenet, C. Couteau, E. Paparis, and L. J. M. Coiffard, "Quercetin and rutin as potential sunscreen agents: determination of efficacy by an in vitro method," Journal of Natural Products, vol. 71, no. 6, pp. 1117-1118, 2008.

[33] R. Casagrande, S. R. Georgetti, W. A. Verri Jr., D. J. Dorta, A. C. dos Santos, and M. J. V. Fonseca, "Protective effect of topical formulations containing quercetin against UVB-induced oxidative stress in hairless mice," Journal of Photochemistry and Photobiology B, vol. 84, no. 1, pp. 21-27, 2006.

[34] R. Hirano, W. Sasamoto, A. Matsumoto, H. Itakura, O. Igrashi, and K. Kondo, "Antioxidant ability of various flavonoids against DPPH radicals and LDL oxidation," Journal of Nutritional Science and Vitaminology, vol. 47, no. 5, pp. 357-362, 2001.

[35] V. Cody, E. Middleton Jr., and J. B. Harborne, Plant Flavonoids in Biology and Medicine: Biochemical, Pharmacological and Structure-Activity Relationships, Alan R. Liss, New York, NY, USA, 1985.

[36] B. Li and D. F. Birt, "In vivo and in vitro percutaneous absorption of cancer preventive flavonoid apigenin in different vehicles in mouse skin," Pharmaceutical Research, vol. 13, no. 11, pp. 1710-1715, 1996.

[37] A. Saija, A. Tomaino, D. Trombetta, M. Giacchi, A. De Pasquale, and F. Bonina, "Influence of different penetration enhancers on in vitro skin permeation and in vivo photoprotective effect of flavonoids," International Journal of Pharmaceutics, vol. 175, no. 1, pp. 85-94, 1998.

[38] A. Svobodová, J. Psotová, and D. Walterová, "Natural phenolics in the prevention of UV-induced skin damage. A review," Biomedical Papers, vol. 147, no. 2, pp. 137-145, 2003.

[39] M. Dueñas, F. Surco-Laos, S. González-Manzano, A. M. González-Paramás, and C. Santos-Buelga, "Antioxidant properties of major metabolites of quercetin," European Food Research and Technology, vol. 232, no. 1, pp. 103-111, 2011.

[40] H. Pool, D. Quintanar, J. de Dios Figueroa, J. E. H. Bechara, D. J. McClements, and S. Mendoza, "Polymeric nanoparticles as oral delivery systems for encapsulation and release of polyphenolic compounds: impact on quercetin antioxidant activity \& bioaccessibility," Food Biophysics, vol. 7, no. 3, pp. 276-288, 2012.

[41] E. Falkovskaia, P. K. Sengupta, and M. Kasha, "Photophysical induction of dual fluorescence of quercetin and related hydroxyflavones upon intermolecular H-bonding to solvent matrix," Chemical Physics Letters, vol. 297, no. 1-2, pp. 109-114, 1998.

[42] B. M. Fahlman and E. S. Krol, "Inhibition of UVA and UVB radiation-induced lipid oxidation by quercetin," Journal of Agricultural and Food Chemistry, vol. 57, no. 12, pp. 5301-5305, 2009.

[43] E. S. B. Ferreira, A. Quye, H. McNab, and A. N. Hulme, "Photooxidation products of quercetin and morin as markers for the characterisation of natural flavonoid yellow dyes in ancient textiles," Dyes in History and Archaeology, vol. 18, pp. 63-72, 2002.

[44] S. G. Chiodo, M. Leopoldini, N. Russo, and M. Toscano, "The inactivation of lipid peroxide radical by quercetin. A theoretical insight," Physical Chemistry Chemical Physics, vol. 12, no. 27, pp. 7662-7670, 2010. 
[45] P. Pedrielli, G. F. Pedulli, and L. H. Skibsted, "Antioxidant mechanism of flavonoids. Solvent effect on rate constant for chainbreaking reaction of quercetin and epicatechin in autoxidation of methyl linoleate," Journal of Agricultural and Food Chemistry, vol. 49, no. 6, pp. 3034-3040, 2001.

[46] J. B. Zvezdanović, D. Z. Marković, D. J. Cvetković, and J. S. Stanojević, "UV-induced change in quercetin antioxidant activity toward benzophenone initiated lipid peroxidation," Journal of the Serbian Chemical Society, vol. 77, no. 11, pp. 15711588, 2012.

[47] R. O. Recknagel and E. A. Glende Jr., "Spectrophotometric detection of lipid conjugated dienes," Methods in Enzymology, vol. 105, pp. 331-337, 1984.

[48] A. Subagio and N. Morita, "Prooxidant activity of lutein and its dimyristate esters in corn triacylglyceride," Food Chemistry, vol. 81, no. 1, pp. 97-102, 2003.

[49] D. Cvetković, D. Marković, D. Cvetković, and B. Radovanović, "Effects of continuous UV-irradiation on the antioxidant activities of quercetin and rutin in solution in the presence of lecithin as the protective target," Journal of the Serbian Chemical Society, vol. 76, pp. 973-985, 2011.

[50] J. B. Zvezdanović, J. S. Stanojević, D. Z. Marković, and D. J. Cvetković, "Irreversible UV-induced quercetin and rutin degradation in solution, studied by UV-spectrophotometry and HPLC chromatography," Journal of the Serbian Chemical Society, vol. 77, no. 3, pp. 297-312, 2012.

[51] B. M. Fahlman and E. S. Krol, "UVA and UVB radiationinduced oxidation products of quercetin," Journal of Photochemistry and Photobiology B, vol. 97, pp. 123-131, 2009.

[52] V. Krishnamachari, L. H. Levine, and P. W. Paré, "Flavonoid oxidation by the radical generator AIBN: a unified mechanism for quercetin radical scavenging," Journal of Agricultural and Food Chemistry, vol. 50, pp. 4357-4363, 2002.

[53] V. Krishnamachari, L. H. Levine, C. Zhou, and P. W. Paré, "In vitro flavon-3-ol oxidation mediated by a B ring hydroxylation pattern," Chemical Research in Toxicology, vol. 17, pp. 795-804, 2004. 

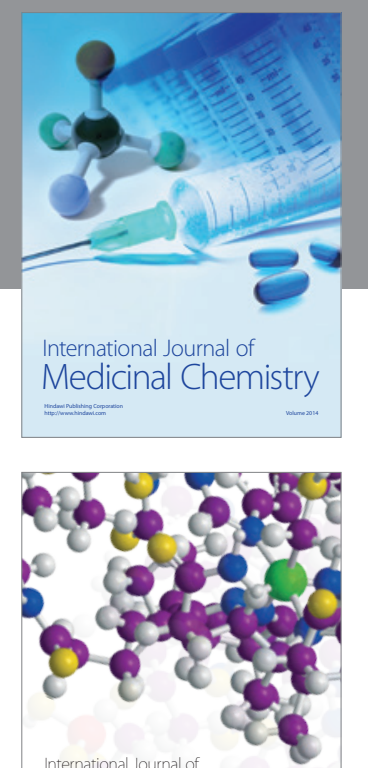

\section{Carbohydrate} Chemistry

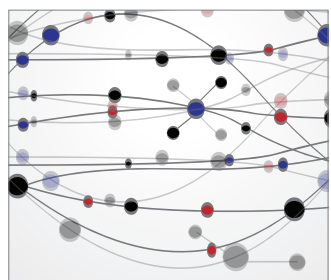

The Scientific World Journal
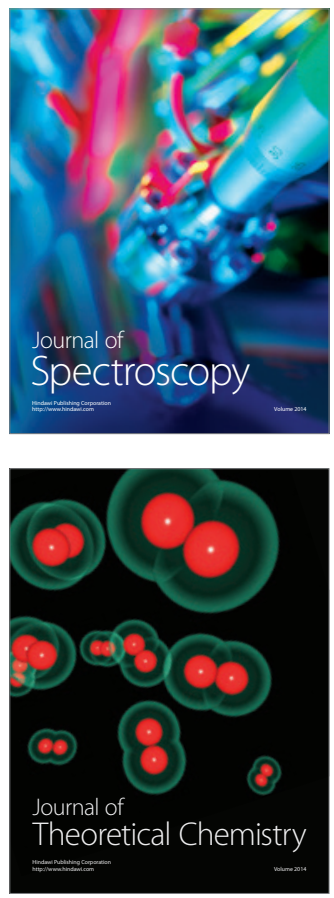
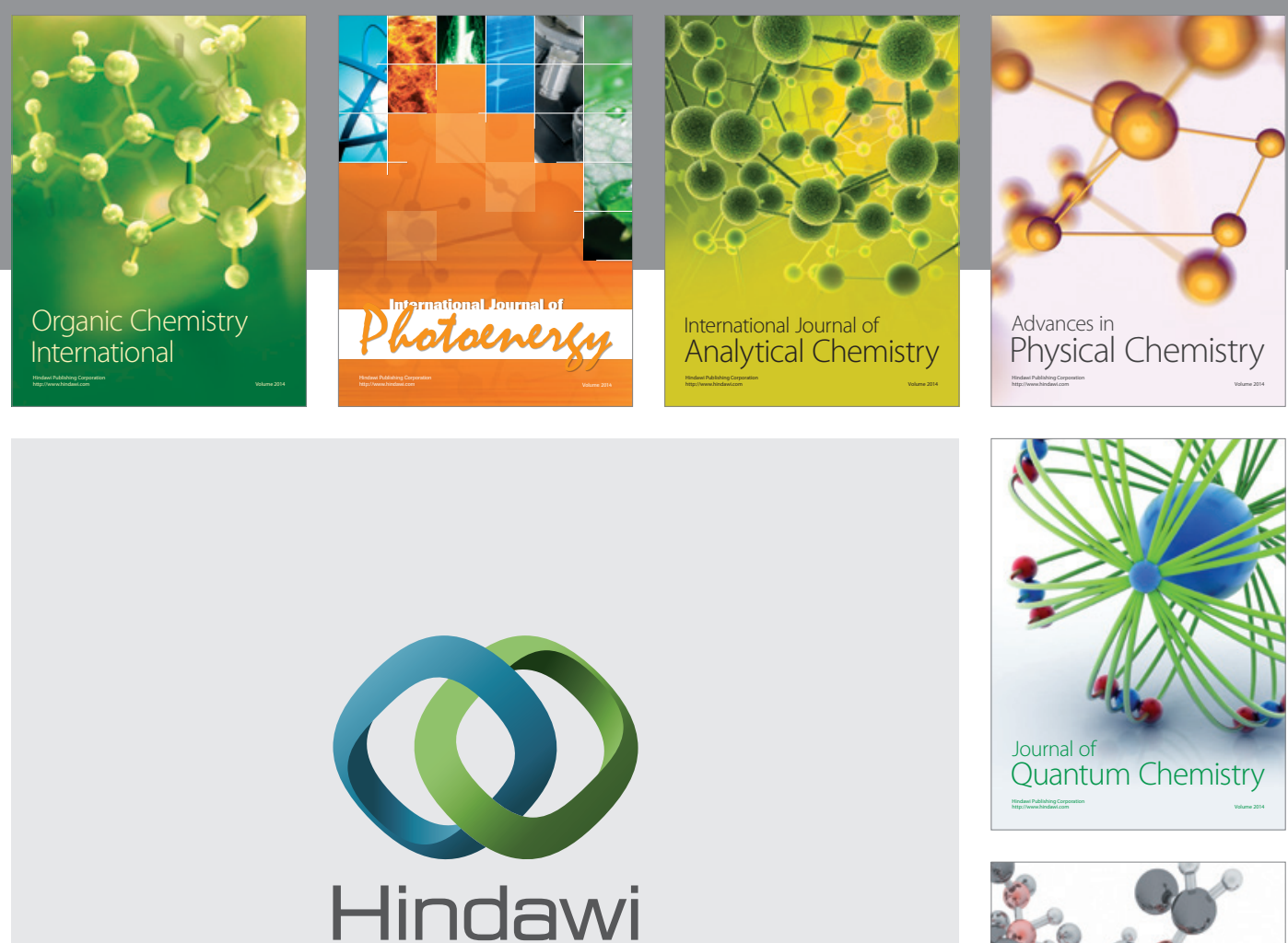

Submit your manuscripts at

http://www.hindawi.com

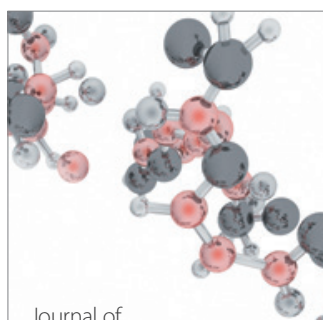

Analytical Methods

in Chemistry

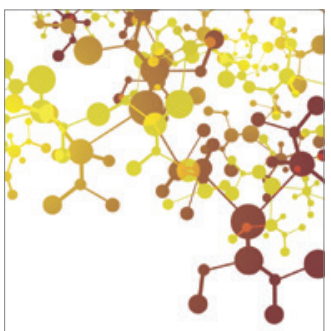

Journal of

Applied Chemistry

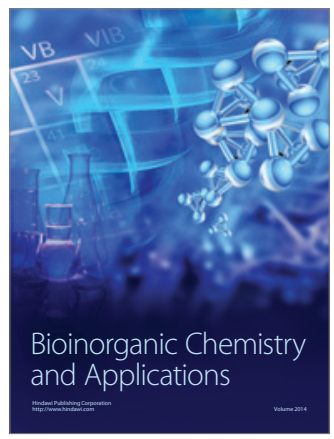

Inorganic Chemistry
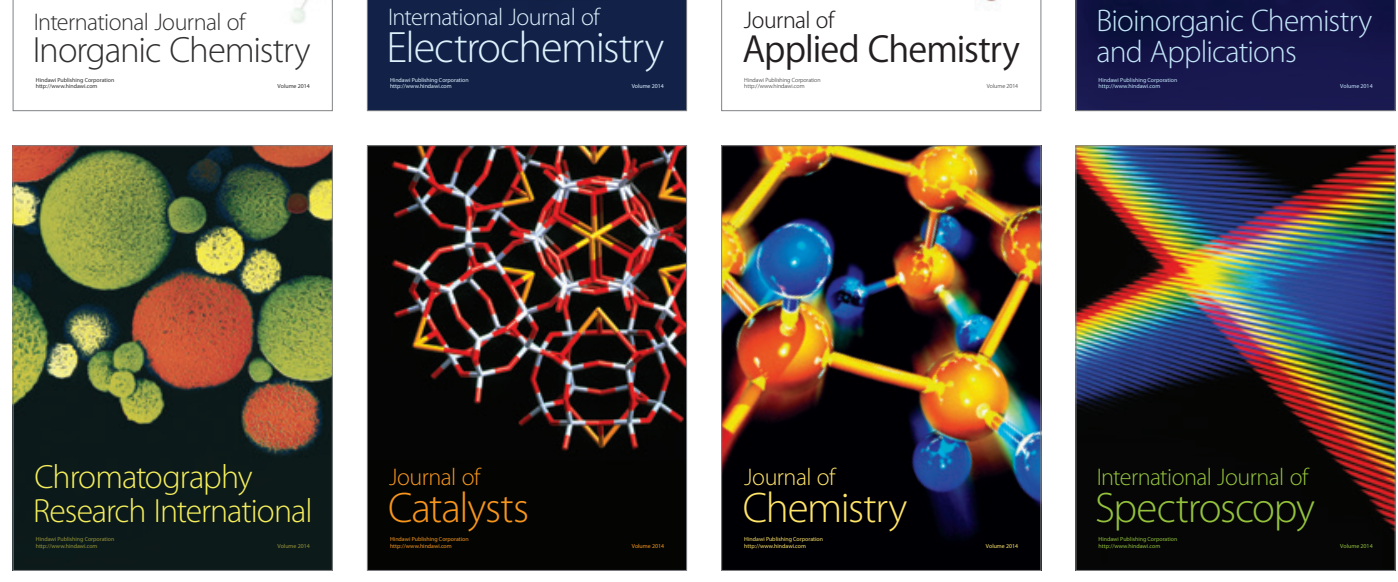